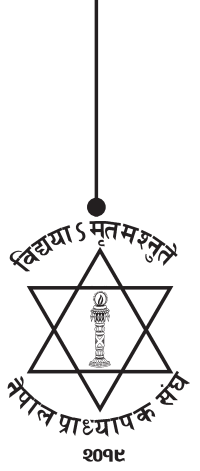

NJ: NUTA

\title{
My Journey from a Waiter to a Lecturer: An Autoethnography
}

\author{
Rajan Binayek Pasa \\ $\mathrm{PhD}$ scholar Tribhuvan University, Faculty of Education \\ PhD scholar Tribhuvan University, Faculty of Humanities and Social Sciences \\ Lecturer, Central Department of Rural Development, Tribhuvan University \\ Email for correspondence: rbpshrestha_1942@yahoo.com
}

\begin{abstract}
This study appraised my momentarily missing twelve years of formal education life (1990-2002) and thoughtful higher education life (2002 to onward). One of the main aims was to ascertain; what are the turning points of my education/working life struggles. In that context, I appraised how I became success to improve my family livelihood by working as a waiter, achieve higher educational status and started my academic career as a lecturer since my engagement with in/formal education. I applied autoethnography as methodology and narrative imagination and writing as inquiry as methods and meditation, self-reflexivity and self-interviewing as major sources of narrative information. While exploring my past, I found, I was ambitious/reflective actor, and rejected the reproduction of my occupational and educational status. I could not become astronaut but I was emotionally committed to perform and produce something unique in my life. Being there, by supporting my family livelihood, I was planning to pledge against stratified socio-economic and cultural structures. I applied vocational rehabilitation therapy and resiliency against my frustration and engaged in working life. My involvement in livelihood not only improved family livelihood but also encouraged me to embark in higher educational voyage. Ultimately, my higher education status and critical thinking ability helped me to transform my life from an anger driven behavior and feelings into happy oriented actions/ interactions with self and others. Being here, after becoming a lecturer, I am seeing myself as a new potential organic intellectual as an outcome of my thoughtful education/working life struggles.
\end{abstract}

Key words: Informal and formal education, family livelihood, higher education, agency and rural development.

\section{Turning Points of my Life}

I was born and brought in remote rural areas of Rolpa and Pyuthan Districts of Mid Western Nepal. With quality parenting, I completed School Leaving Certificate (SLC) in 1990 with district second topper position from Saraswoti Secondary School, Bangesal, Pyuthan. After that, my father asked me to join one year Community Medicine Auxiliary (CMA) training program for continuing medical service to the villagers. I could not convince to him as I wanted to become an astronaut. While replied to my request, my father (key source of motivation in my life) made me clearer that only economically well students can fulfill their higher educational goals (Pasa, 2014). I then committed to improve my

NUTA JOURNAL, 6 (1\&2), 2075 : ISSN: 2616 - 017x 
family livelihood before achieve higher educational status. I was unmarried but became worry with the educational life of my own children as they might face similar situation said by my father and faced by myself. Thoughtfully, I engaged in my working life and informal education life through different types of jobs in Nepal and India. Ultimately, my learning and earning struggles not only improved my family livelihood but also nourished my understanding on different occupational status that encouraged me to retain in higher educational voyage (since 2002 to onward). Because of that at present, I successfully started my academic career as a lecturer in University and I have been spending my daily life with positive hope and feelings that I would become a potential organic intellectual for my society and nation (Monosta, 2000). For me it is possible because of my critical understanding on self and society as well as thoughtful education and working life struggles. While I was a secondary level student, I was more worried with my family livelihood (self). During my learning and earning life in India, I began to worry with poor socio-cultural and economic structures of own and neighboring societies (others). At the same time during my higher educational struggle, I am becoming worry with developmental tag of own country as a least developing country. In this consideration, I am telling my lived stories to the readers that how my learning in ever-changing environments transformed my life and livelihood, feeling and understanding as well my civic role and responsibilities. By this means, I aimed at researching on myself in which I have been reading my experiential world and socio-cultural knowledge as a text and context (Kincheloe \& Steinberg, 1998). To the end, as a researcher, I am sharing my personal voice of experiences and searching contextual truths through my lived experiences. It is related to worth turning point in my working life that has transformed my life from anger-driven thinker to hopefully a sensitive person with inner dispositions for happiness-oriented actions and interactions with self and others.

\section{Research Questions}

- How and why my changing socio-economic condition and dis/empowering cultural structures were compelled to miss my formal education?

- How did my working experiences on diverse socio-cultural contexts encourage me to retain in journey of higher educational struggle?

- How and why have I perceived an empowering and liberating role of higher education?

\section{Research Design}

I begin with research question; what are the turning points of my life and how my involvement in in/formal education and working life in ever changing environment transformed my understanding and responsibilities? My research question aimed to promote moral discourses for stimulating critical conversation about experienced socio-cultural and economic structures (Denzin \& Lincoln, 2011). I was willing to collect narrative texts related to my interactions with self and others (O'reilly, 2005) to understand my personal attitude, feelings, activities, and behavior by contextualizing my past and present events (Cohen et al., 2007). I was trying to present my confronted decisions, dangerous or miserable bends of my past and present working life and powerful critiques on interactions with family and society (Silverman, 2004).

I applied autoethnography as methodology and narrative imagination and writing as inquiry as methods to generate narrative meanings (Hamersley \& Atkinson, 1995). Autoethnography is about my personal biographical information within a foundation of various social and cultural contexts (Denzin \& Lincoln, 2011). I wanted to critique on personal working lives that would intersects with my

NUTA JOURNAL, 6 (1\&2), 2075 : ISSN: 2616 - 017x 
experienced social and cultural issues (Pena, 2000 as cited in Spry, 2011). Further, I have emphasized my turning points of working life within a layer of interpretations rather than only telling biographical stories (Saldana, 2008 as cited in Chase, 2011). By applying method of narrative imagination, I wanted to recall my critical conversations with self (me) and others (society) so that I could generate and understand consequences of such conversations over time (Chase, 2011). And by applying method of writing as inquiry, I constructed my narrative imagined texts and contexts more rigorous by thinking more structurally and reflectively.

Similarly, I applied meditation, self-reflexivity and self-interviewing as major sources of narrative data because researcher myself was a primary source of data collection (Denzin, 2008 as cited in O'reilly, 2005). I applied milder forms of meditation for memory reconstruction so that I could visualize and recall my turning points of life. I used self-reflexivity for changing visualized forms into internal conversation to generate narrative information with the critical reflection (Muncey, 2005). During reflexive thinking, I also used my potential skills and abilities to valuing good reasoning power and constructs new belief and action on my working and education life (Baillin \& Pendlebury, 2003). I have come to realize that my self-reflexivity power has been oriented for exploring self-knowledge through self-appraising (Gecas \& Burke 1995 as cited in Pagis, 2009). And, I applied interview as a part of self-interview (Crawley, 2012 as cited in Belbase, 2013) in which I virtually played my role from researcher in to research participant (Belbese, 2013). I raised my questions then responded myself through critical review of my past and present experiences.

\section{Journey of Livelihood Struggles}

My father voluntarily kicked out his job three years before he would qualify for his pension. In such a situation, I passed school education with higher expectation. After then, fortunately or unfortunately, my father run first medical store for providing uneconomic services to the villagers. At a time, being an elder son, I was experiencing changing economic status (moderate to poor) and losing socio-economic status of my parents. However, I was proud with various skills of my parents. My father was popular due to his multiple skills and government job. He had participated in different skill development trainings related to agriculture, health, music, dance, singing, painting and fine arts etc. My father wore different hats; he was known as a singer, comedian, dancer, artist, painter, kind hearted public servant, as well as a health worker known by many people throughout the districts (Pasa, 2014). My mother was also a health worker, a teacher and a skillful woman. She still makes various types of embroidery goods during her leisure time. Being her loving elder son, I was appraising her worry and misery as she was becoming weaker and reserve typed day by day. Perhaps she was more worried with my vulnerable higher education life and family livelihood.

Instead of supporting to my expected higher education life, my relatives and local intellectuals used to repeat poor economic condition of my parents became obstacle for my higher education. In this situation I also became worried with poor social and economic support system practicing in my village that made me a bit frustrated. But I understood, my social category is defined along stereotypical as held in culture that was about normative and I made my strong commitment to increase my social category, class and role qualitatively (Turner et al. 1987 p. 230 as cited in Stets \& Bruke, 2000). Knowingly or unknowingly, I decided to struggle myself against poor family livelihood, personal sufferings, and bondages through peace and happiness. Perhaps, I became close to four supreme truths of Buddhism 
that (I) there is suffering in the world, (II) there are causes of suffering, (III) suffering can be addressed and (IV) suffering can be addressed by eight-fold paths (Kharel et al., 2011). I then visited Lumbini, the birth place of Lord Buddha for searching peace and power before I kick off my working life.

How could I involve for supporting to the livelihood of my parents? I raised this question many times to search answer so that I could choose productive working life. In such a critical situation, I was obliged to improve economic condition; I had to increase my educational status out of my working life. I came to realize that I was suffered from many problems (i.e. social, economic, educational and cultural) that have enforced my life journey in to anguish. I planned to leave my village many times but I could not. I had no idea that which area could be productive for supporting the livelihood and where I could develop my professional career. Fortunately, my sister- in- law suggested me to engage in teaching profession in institutional school and continue my higher education simultaneously. This could be a better strategy for my expected life struggle. Thereby, I started my working life from teaching profession. But instead of that I became worried and I might felt impossibility to change economic condition from minimal earnings. I became weaker and frustrating day by day due to worrying my stressful feeling and behaving. I wanted to change my working life in another environment where I can share my problems among peer groups.

After quitting my teaching profession, I purposefully started volunteer hostel warden service to guide secondary level students. Hostel was/is located quite nearer from my home. During my school age, I learnt some skills from parents and several life skills like; swimming, fishing, singing, dancing, playing physical games, climbing tree from neighboring Dhami children (Pasa, 2011). I started sharing those skills, curricular knowledge and extracurricular practices among more than thirty students. I so doing, I improved my leadership skill, and also played counseling and motivating role to the students. Up to this point, I can say that we were applied collaborative learning process through liberation pedagogy for addressing isolation as we used to provide equal learning and performing opportunities to all students (Ann \& Berthoff, 1990). During that period, we engaged in yoga, meditation and martialarts class early in the morning, engaged in tuition class before and after school time and engaged in various life skills class (i.e. singing, dancing, and playing musical instruments) in the evening time. Sometimes, we stole seasonal fruits and vegetables from our neighboring villages. Apart from this and that I also visited my friends' villages where I got a chance to interact with many faces that increased my level of confidence. I became capable to reduce my stress, fear, sadness, guilt or anger and also developed my ability to cope successfully with challenging situation and adjust in new destinations (Davidson et al., 2005).

While I was working as a hostel warden, one day, I visited my junior friend's home. Fortunately, I got a chance to meet with his elder brother, continuing his higher education and working life in capital city, Kathmandu. I planned to do accordingly, so that I could struggle independently. I emotionally reached capital city with my junior friend but we could not get any kind of support from others (relatives and friends). We compelled to work as a labor for couple of weeks around Bhaktapur area. Again I decided to visit India for job opportunities where I might get support from my neighboring friends. I reached Govindgardh, Punjab and met with my villagers and visited popular Gurudwaras (i.e. religious place where Punjabi people used to worship and pray), gardens, parks, steel factories, hotels and restaurants. After a long refreshment visit, I got fifteen days security guard training with help of my 
neighboring friends and worked as a security guard for few months. Fortunately, I became close with some Punjabi young (we used to play volleyball, badminton and roller skating together) who supported me to work as a storekeeper in hotel. However, I understood, joining this job was impossible without my school level certificate and communicative and numeric skills. At a time, I mostly interacted in English language with hotel manager. My manager voluntarily taught me theoretical knowledge on food and beverage and housekeeping service for eighteen months. Apart from my job responsibility, I had to serve bed tea, breakfast, lunch and dinner for my manager and I also used to keep his room clean. I came to realize that it was for practical implication of theoretical knowledge that he taught me. I began to learn and earn more than previous job. At the same time, because of my friendly behavior and multiple skills; I became popular during inter hotel sports competitions in the city.

At a time, I got letter sent by my father where he had written that he met with Prime Minister of Nepal (my relative grandfather) for possible recommendation to my appointment in a government job. I knew that in our culture, who join government job can achieve higher social status and prestige than others. May be or may not be due to such cultural understanding my parents also wanted to join me in police recruitment. To the end, I returned village after two years and reached Nepalgunj city. I was selected for police recruitment training but during training I could not enjoy it was hopeless and feeling less to me. I was expected to improve my economic condition and educational status too. But during that period, instead of work place learning, I compelled to experience with such environment where there was no humanity, no polite speech, no respect, and no softness. I got only humiliation and frustration intrinsically though I was popular among recruits and trainers because of multiple skills and physical fitness. I became worried on my noble paths: right vision, right action, right speech that I had been applying for solving my suffering and misery (Moore \& Bruder, 2005). It is the reasoned behind why after few months, I again kicked out this job.

\section{Journey of Learning by Travelling}

After quitting government job, I again returned back to Punjab where I had spent more than two years. I was planning to start my working life in the post of hotel/restaurant waiter and wanted to visit many tourism destinations. I got a chance to become a waiter in newly opened hotel and restaurant in another city. As a waiter, I played a key role for receiving and serving food and beverages to the guests. I got a chance to learn about self-discipline, attitude and behavior of the guests. I came to realize that tourism entrepreneurs have been providing productive guest-host relationship by the single formula fitting "Guest is always right!" so that guests could get satisfaction from good Food and Beverage (F\&B) SERVICE (i.e. smiles for every guest, excellent in every activities held among guest and host, reaching to every guest with hospitality, viewing every guest as special, inviting guest to return again, creating warm atmosphere and, every contact that could make hosts care). It might have focused on providing good service to guests as they expected to behave during service. Sometimes I wanted to suggest local stakeholders to provide similar services in the schools for ensuring equal learning opportunities.

As a waiter, during my working life in tourism sectors for more than twelve years, I got a chance to acquire my personal life skills and participate in vocational and skill development trainings. I agree that changing workplace as an environment for learning new skills and knowledge that enable coworkers to better participate in everyday, work-related activities for supporting, valuing and developing opportunities (Clus, 2011). Basically, from my ever changing work place, I got opportunities to learn 
physical life skills (e.g., taking a right posture), behavioral life skills (e.g., communicating effectively), or cognitive life skills (e.g., making effective decisions) (Danish \& Donohue, 1995). During those periods, I interacted with inter/national guest in ever changing environment. Through those interactions, I acquired various insights though I could not get any degree or diploma. In the reference of acculturation and socialization process (Ritzer \& Smart, 2001), I can say that I acquired knowledge on importance of reading, travelling behavior and personal management activities in human life from western culture. At a time, I reviewed various books related to biography of popular scientists, scholars, leaders as well as business man and personality development for controlling my bellicosity (Fischer, 2008). I also understood contributions of tourism and agricultural based activities in rural development process especially in North India. My learning began to change my level of thinking, attitude, behavior and daily activities. I saw myself as a possible change agent as I could replicate tourism and agricultural activities in the society. I began to think that it was almost impossible without my higher educational status. Through this realization, I happily developed my long term higher educational plan. Based on that plan, I rejoined in higher education in 2002 after twelve years of completion of grade tenth. As a private student, I passed Intermediate in Arts (IA) in 2004 and Bachelors in Arts (BA) in 2007 from Mahendra Multiple Campus, Bharatpur (Dang).

\section{Journey of Interdependent Leadership}

My in/formal learning ultimately motivated me to again involve in my journey of interdependent leadership. During BA study, I have come to know that sociological knowledge cultivated revolutionary ideas (critical thinking) in my mind that helped me to see the social issues from different aspects like cultural, educational and political (Kougioumoutzaki, 2007). I planned to play leadership role for replicating those critical thinking into social development process. Owing to the sociological idea on social agents, I found that I was not a passive bearer of structural dominations but a reflective and active social agent having unseen capacity for playing agency role in a society (Archer, 2010). I became institutional member of Rapti Basin Development Society, a non-government organization established in our village. I was sure that without institutional capacity it is impossible to achieve developmental goals. The idea pinched me day by day and finally I enrolled in Master in Arts in Rural Development subject in Central Department of Rural Development Kirtipur in 2008. I wanted to provide quality parenting to my children and achieve higher educational status.

Ultimately, with hard working support of my beloved wife and her quality parenting, my children have been securing topper position in the class. I also completed Master Degree with distinction division in 2011 and I supposed to see myself as a Rural Development expert. At a time we Rural Development graduates of seventh batch, together planned to register national level non-government organization. Before doing so, we involved in ToT (Training on Trainers) training in Training Institute for Technical Instruction (TITI), Bhaktapur. We individually invested for skill development trainings such as; social mobilization, community development, participatory rural appraisal, proposal and report writing and participatory project monitoring and evaluation trainings in Kathmandu Training Center Balkumari, Lalitpur. We also participated in mushroom cultivation training as we wanted to run both profit and non-profit motive organizations. Owing to myself, during our organizational effort I got a chance to empower my leadership capacity and technical ability while I developed collaborative relationship with other stakeholders like; individuals, households, communities, local government and NGOs (Willis, 
2005). Again I enrolled in MPhil for nourishing my horizon of theoretical and philosophical knowledge on education and development. I was also planning to build social networks with skilled professionals and academicians. Again as a topper ranked student, I completed MPhil in Development Studies in 2014 from Kathmandu University. At present being a PhD scholar, I am exploring interfaces among education, tourism and rural development for contributing a body of knowledge (an alternative model of rural development). And being a lecturer, I am motivating/encouraging students to become creative, critical and reflective actor or agent before starting their academic and professional careers.

\section{Theoretical Reflection}

Reflecting upon my thoughtful working and education life struggles, I am quite nearer from my strategic end (becoming a $\mathrm{PhD}$ scholar). I am seeing myself as a potential organic intellectual for own society and nation. I able to experience with role of transformative education and working life but in this transformation, I surpassed through innumerable ups and downs. Before involving in working life, I was one of the most frustrate youth in my village. I was compelling to wander in higher educational interval. At the same time, during the beginning of my working life I was worry to improve my economic condition but later wards; I began to worry with poor social, cultural and economic structures of my society and nation (Ritzer \& Smart, 2001).

Speaking from the vantage point of social stratification theory, I agree that there were $2-5 \%$ elite groups [first ranked], 10-15\% medium groups [second ranked] and 70-75\% mass individuals [third ranked] in my society (Weber as cited in Swedberg, 1998). Reflecting to this principle, I saw myself as a mass individual [third ranked] that is why my parents could not dare to made me astronaut. I must say that this principle has given critical insights in my mind that helped me to conceptualize to change my social and economic ranking. However, in the starting phase, I was going to be a frustrated because I have no idea about productive work place from where I could earn enough. Managing to my frustration, I became volunteer hostel warden and involved in collective learning among students. We also engaged in sharing and caring personal aims, physical and spiritual exercises (yoga and meditation). In doing so, I was applying vocational rehabilitation therapy for maintaining personal, emotional and psychological health and wellbeing (Davidson et al., 2005). During my working life in ever changing environment, according to Vygotsky's theory of socio-cultural learning, I successfully participated in informal/ non-formal learning process in individual and social level (Turuk, 2008). Through these learning, I might have seen the relationship between my positive view and life satisfaction and understand myself worthily and developed ability to plan about my personal life.

I have also come to realize that my transformative education and working life struggle become possible only because of my resilient will and inner urge to constantly learn at any given situation. Owing to my learning and copying style, I applied resilient against all sorts of psychological and emotional distresses in my in/formal education and working life (Maddi, 2005). At this moment, I can say that my personal capacity, intellectual ability, easy temperament, communicative skills and autonomy have developed with my effective coping strategy and resiliency (Brooks, 1994). My coping strategies have cropped my personal characteristics in a dynamic process that involved interaction of inter-personal knowledge, disposition and skills. Finally, from the perspective of structure and agency theory, my personal and institutional agentic role has been orienting upon making and remaking of socio-cultural and economic structures through ongoing self-transforming actions and perceptions 
(Giddens, 1984). During the beginning of my interdependent leadership role, I was willing to change poor structures of own society. But during my higher education life, I understood transformative role of education that can empowers youths (male and female) by increasing their chances of getting jobs and participating fully in society (United Nations Educational, Scientific and Cultural Organization [UNESCO], 2013). This is the reason behind why I am planning to perform social role of education as for unpacking my capabilities and fulfilling own civic responsibilities very soon rather than revolving in personal pride, emotion and ego.

\section{My Understanding}

I have come up with conclusion that my involvement in in/formal education and trainings in ever changing environment made me more critical and reflective. My transformative life motivated me to appraise my life from various perspectives like; social, economic and educational. Being there, I understood my school education life began with supporting orientation, quality parenting and motivation, and ended with poor parenting, suffering and bondage. I was ranked as a socio-economically poor student because of social stratification but I was emotionally committed to perform and produce something unique in my life. I had had a high expectation from my thoughtful working life that improved my family livelihood ultimately. Even though, during that period, I used to feel, if something is lacking in my life journey though I changed my social identity with achieved status and capitals. Because of that gain, I planned to increase my educational status for my implicit goals and embarked on my higher educational voyage, and played an interdependent leadership role simultaneously. I understood that my involvement in ever changing working and education life and critical thinking ability helped me to transform my life from an anger driven behavior and feelings into happy oriented actions and interactions with self and others, happiness, liberated and empowered (Omotoso, 2003). Finally being here, during my life-long learning process, I have reflectively gone through four stages of learning; learning to know, learning to do, learning to be and learning to live together (Delors, 1996). My learning in ever changing environment made me moral and responsible. I have not only transformed my life and livelihood but also playing quality parenting role to my children and motivational role to my thoughtful students. I have also been playing supportive and counseling role to the local youths and planning to transform socio-cultural and economic structures of my own society through institutional agency role (Gidden, 1984). Finally, my reflection on turning points of my education and working life struggles, can become an inspiration to the students studying in different Colleges and Universities as well as youths working in inter/national labour market. Finally, youths who are still missing their higher education life and improving their family livelihood can get inspirations from these transformative insights explored during my reflection.

\section{References}

Ann, E. \& Berthoff, A. E. (1990). Paulo Freire's liberation pedagogy. Language Arts, 67 (4), 362-369. Retrieved from http://www.jstor.org/stable/41961745

Archer, M. S. (2010). Routine, reflexivity, and realism. Sociological Theory, 28 (3), 272- 303.

Bailin, S. \& Siegel, H. (2003).Critical thinking. In N. Blake, P. Smeyer. R. Smith \& P. Standish (Eds.), Philosophy of education (pp. 38-56). Berlin: Blackwell Publishing.

Belbase, S. (2013). Beliefs about teaching geometric transformations with geometers' sketchpad: A reflexive abstraction. Journal of Education and Research, 3 (2), 15-34.

NUTA JOURNAL, 6 (1\&2), 2075 : ISSN: 2616 - 017x 
Burke, P. (Ed.). (1992). Critical Thought Series. Two critical essays on Michel Foucault. Cambridge: The University Press.

Chase, S. E. (2011). Narrative inquiry: still a field in the making. In N. K. Denzin (Ed.).Handbook of arts in qualitative research (pp. 117-125). London: Sage Publication.

Clus, M. L. (2011). Informal learning in the workplace: A review of the literature. Australian Journal of Adult Learning, 51 (2), 355-373.

Cohen, L., Manion, L., \& Morrison, K. (2007). Research method in education (6th ed.) London: Taylor $\&$ Francis Group.

Danish, S.J., \& Donohue, T. (1995).Understanding media's influence on the development of antisocial and prosocial behavior. In R. Hampton, P. Jenkins, \& T. Gullota (Eds.), Preventing violence in America (pp. 133-156). Thousand Oaks, CA: Sage.

Davidson, J. R. T., Payne, V. M., Connor, K. M., foe, E. B., Rothbaum, B.O. \& Hertzberg, M .A. (2005).Trauma, resilience and saliostasis: Effect of treatment in post-traumatic stress disorder. International Clinical Psychopharmacology, 20, 43-48.

Delors, J. (1996). Learning: the treasure within. Paris: UNESCO

Denzin, N. K. \& Lincoln, Y. S. (2011). Handbook of qualitative research (4thed.). London: Sage Publication.

Fischer, M. (2008). Mead and the international mind. Transactions of the Charles S. Peirce Society, 44 (3), 508-531.

Giddens, A. (1984). The Constitution of Society: Outline of the Theory of Structuration. Cambridge, UK: Polity Press. p. 258.

Kharel, M., Timilsina, B. K., \& Bhandari, A. L. (2011). Philosophical foundation of education. Kathmandu: Student Book Publication and Distribution.

Kincheloe, J. L., \& Steinberg, S. R. (1998). Lesson plans from the outer limits: Unauthorized methods. In J. L. Kincheloe\& S. R. Steinberg (Eds.), Unauthorized methods: strategies for critical teaching. New York: Routledge.

Kougioumoutzaki, F. (2007). The "adventures" of the sociology course in Greek secondary education. The American Sociologist, 38 (2), 191-210. Springer. Retrieved from URL:http://www.jstor. org/stable/27700499

Maddi, S. R. (2005). On hardiness and other pathways to resilience. American Psychologist, 60, 261262.

Monosta, A. (2000). Antonio Gramsci, prospects. The Quarterly Review of Comparative Education, 23 (3-4), 597-612.

Moore, B. N., \& Bruder, K. (2005). Philosophy: The power of ideas( 6th ed.).New York, NY: The McGraw-Hill Companies.

Muncey, T. (2005). Doing auto ethnography. International Journal of Qualitative Methods 4(1), 1-12.

O'reilly, K. (2005). Ethnographic methods. London: Routledge.

Omotoso, S. A. (2003). Education and emancipation: An African philosophical perspective. The journal of Pan African studies, 3 (8), 226-251.

Pagis, M. (2009). Embodied self-reflexivity. Social Psychology Quarterly, 72 (3), 265-283. 
Pasa, R. B. (2011). Socio-economic situation and cultural practices of Dhami community in Pyuthan: A case study of Dhami Community of Bangesal, Pyuthan. (An Unpublished MA Dissertation). Submitted to Central Department of Rural Development. Tribhuvan University, Kirtipur, Kathmandu.

Pasa, R.B. (2014)."Sa Vidyaya Vimuktaye" Changing Perceptions on In/formal Education: My Journey from a Waiter to a Researcher. (An Unpublished MPhil Dissertation). Submitted to Kathmandu University, School of Education, Dhulikhel.

Ritzer, G. \& Smart, B. (Eds.) (2001). Hand book of social theory. London: Thousand oak Sage Publiction.

Ritzer, G. (2000). Sociological theory (5th ed.). Singapore: McGraw -Hill.

Spry, T. (2011).Performance auto ethnography. In N. K.Denzin (Ed.), Interpretive biography. Handbook of arts in qualitative research (pp.117-125). London: Sage Publication.

Stets, J. E. \& Bruke, P. J. (2000).Identity theory and social identity theory. Social Psychology, Quarterly, 63 (3), 224-237.

Swedberg, R. (1998). Max Weber and the idea of economic sociology. Princeton: Princeton University Press.

Turuk, M. (2008). The Relevance and Implications of Vygotsky's Sociocultural Theory in the Second Language Classroom . ARECLS, 5, 244-262.

United Nations Educational, Scientific and Cultural Organization (UNESCO) (2013). Education transforms lives. Education for all global monitoring report. UNESCO Publication. 